\title{
Mobilizando saberes docentes na educação física escolar: a construção do conhecimento sobre inclusão
}

\author{
Victor Julierme Santos da Conceição* \\ Hugo Norberto Krug** \\ Edna Venson***
}

Resumo

Este estudo objetivou compreender como os professores buscam o conhecimento sobre a inclusão, para atuar com os Alunos com Necessidades Educacionais Especiais (ANEE), incluídos nas aulas de Educação Física em turmas comuns do ensino fundamental. Participaram desta pesquisa três colaboradoras, professoras de Educação Física regentes de classe no ensino fundamental. Como instrumento para a coleta de dados foi utilizada uma entrevista semiestruturada, cujas informações foram transcritas e analisadas através do levantamento das unidades de significado e construção de categorias de análise. Os resultados mostraram que as três professoras entrevistadas tiveram contato direto com a Educação Física durante a sua vida escolar, bem como com o esporte de rendimento. Isso fez com que as mesmas optassem pela formação na área, e foi somente depois de terem um aluno incluído em suas aulas, é que foram em busca de uma especialização sobre a inclusão na Educação Física Escolar.

Palavras-chave: Educação inclusiva; Saberes docentes; Formação de professores.

\footnotetext{
* Professor Mestre do Curso de Educação Física da Universidade do Extremo Sul de Santa Catarina - Doutorando no Programa de Pós-Graduação em Ciências do Movimento Humanol UFRGS. Criciuma, Santa Catarian - Brasil.

** Professor Doutor do Curso de Educação Física da Universidade Federal de Santa Maria e do Programa de Pós Graduação em Educação da Universidade Federal de Santa Maria. Santa Maria, Rio Grande do Sul.

*** Professora de Educação Física da Universidade do Extremo Sul de Santa Catarina. Criciuma, Santa Catarian - Brasil.
} 


\title{
Mobilizing knowledge in physical education teacher education: building the knowledge of inclusion
}

\begin{abstract}
This study aimed at understanding how teachers seek knowledge about inclusion, to work with Students with Special Educational Needs, included in physical education classes in ordinary elementary school classes. Participated in this study three Physical Education teachers, regents class in elementary school. Was used a interview with teacher about study objective. The information was transcribed and analyzed through a survey of the meaning units and construction of analytical categories. The results showed that the three teachers interviewed had direct contact with the physical education during their school life, as well as the sport of income. The teacher traning happens only the teacher of faces with student included.
\end{abstract}

Keywords: Inclusive education; Teacher knowledge; Teacher training.

\section{Considerações iniciais}

O professor e a escola, onde este exerce a sua prática educativa, são responsáveis pela possibilidade de construção de conhecimentos e de saberes que são mobilizados a partir da cultura escolar. É também através da prática docente, que o professor, aos poucos, vai adquirindo capacidades e competências para um trabalho positivo com os Alunos com Necessidades Educacionais Especiais (ANEE).

Destacamos a Declaração de Salamanca (1994) que menciona que o princípio fundamental das escolas inclusivas consiste em todos os alunos aprenderem juntos, sempre que possível, independentemente das dificuldades e das diferenças que apresentem. Estas escolas devem reconhecer e satisfazer as necessidades diversas dos seus alunos, adaptando-se aos vários estilos e ritmos de aprendizagens, de modo a garantir um bom nível de educação para todos.

Mazzotta (1993) observa que são necessárias modificações na organização e no funcionamento da educação escolar, para que os ANEE possam ser atendidos. Faz parte da inclusão, criar um ambiente onde todos 
os alunos possam desfrutar o acesso e o sucesso no currículo e tornaremse membros totais da comunidade escolar e local, sendo deste modo valorizados.

Já Mittler (2003) relata que o objetivo de tais modificações é garantir o acesso e a participação de todos os alunos em todas as possibilidades oferecidas pela escola e impedir a segregação e o isolamento. Estas modificações são necessárias nas escolas, para que permitam total inclusão dos alunos, sem que eles se sintam impotentes diante das diferenças. $O$ mesmo autor, ainda destaca que não basta os alunos serem apoiados para terem acesso ao que está disponível nas escolas.

Voivodic (2004) comenta que se a educação é importante, como fator de transformação para todos os indivíduos, uma educação de qualidade, que atenda suas necessidades educativas especiais, torna-se fundamental para os indivíduos com deficiência. Assim, para que os ANEE tenham uma educação de qualidade, é preciso ter professores qualificados para trabalhar com a inclusão, professores dispostos a passar por mudanças durante sua carreira, aprimorando constantemente seu saber docente, buscando conhecimentos para que a inclusão de fato aconteça.

Para Bueno (2002) não são somente os programas de formação de professores que contribuem para a construção da identidade docente, mas, também, suas experiências de vida relacionadas à educação. Tardif (2004) observa que este é o saber temporal, é adquirido no contexto de uma história de vida e de uma carreira docente. Destaca, que a construção da identidade do professor inicia na infância, e se torna estável na formação inicial, dando continuidade durante toda sua carreira profissional. Gauthier (1998) salienta que os saberes nos quais os professores se apóiam dependem diretamente das condições sociais e históricas nas quais eles exercem sua docência.

Tardif (2004) coloca que o professor é considerado o sujeito ativo de sua própria prática, quando a aborda e a organiza a partir de sua vivência, de sua história de vida, de sua efetividade docente e de seus valores. Cada professor organiza suas aulas também da maneira que lhe é mais oportuna perante as suas condições de trabalho, podendo ainda utilizar-se de conhecimentos trazidos em sua bagagem de vida, enquanto aluno na escola. Este autor relata que o desenvolvimento do saber profissional é associado tanto às suas fontes e lugares de aquisição quanto aos seus momentos e fases de construção.

Freire (2001) afirma que é preciso, sobretudo, que o professor desde o princípio, assuma-se como sujeito da produção do saber, e se convença 
definitivamente de que ensinar não é somente transferir conhecimento, mas criar as possibilidades para a sua construção. O professor precisa estar sempre se atualizando, através das mais variadas formas, para assim, poder ter um conhecimento que possa levar à cabo frente às dificuldades encontradas durante o exercício da profissão, podendo assim tornar-se um bom professor.

Tardif (2004) destaca que os saberes são provenientes de diversas fontes tais como: a) Os saberes da formação profissional, que são o conjunto de saberes transmitidos pelas instituições de formação de professores. O professor e o ensino constituem objetos de saber para as ciências humanas e para a ciência da educação. Não se limitam a produzir conhecimentos, mas procuram também incorporá-los à prática do professor. Estes conhecimentos se transformam em saberes destinados à formação cientifica ou erudita dos professores, e, caso sejam incorporados à prática docente, esta pode transformar-se em prática cientifica, em tecnologia da aprendizagem. A articulação entre estas ciências e a prática docente se estabelece, concretamente, através da formação inicial ou contínua dos professores; b) Os saberes disciplinares, que integram-se igualmente à prática docente através de formação (inicial e contínua) dos professores nas diversas disciplinas oferecidas pela universidade e correspondem aos diversos campos de conhecimento, dispostos na sociedade, integrados nas universidades, faculdades e cursos como disciplinas; c) Os saberes curriculares, que são saberes que os professores se apropriam ao longo de sua carreira. Correspondem aos discursos, objetivos, conteúdos, metodologias. São programas escolares que os professores devem aprender e aplicar; e, d) Os saberes experienciais ou práticos, que são os saberes específicos que os próprios professores desenvolvem de acordo com a prática da sua profissão, em seu cotidiano. Estes saberes brotam da experiência e são por ela validados. Assim, a prática pode ser vista como um processo de aprendizagem através do qual os professores (re)traduzem sua formação e a adaptam à profissão, eliminando o que lhes parecem inutilmente abstrato ou sem relação com a realidade vivida e conservando o que pode servir-lhes de uma maneira ou de outra.

Assim, o caminho teórico traçado até este momento, fomentou a construção do seguinte objetivo deste estudo: compreender como os professores buscam o conhecimento sobre a inclusão, para atuar com os ANEE incluídos nas aulas de Educação Física em suas turmas comuns do ensino fundamental.

A iniciativa de pesquisar sobre a mobilização dos saberes docentes de professores de Educação Física, a partir da prática educativa em situações de inclusão escolar, surge e se justifica por meio das observações e debates 
sobre as práticas pedagógicas destes professores, pois, constantemente, os docentes trazem à tona questões que apoiam o pensar e o resignificar a inclusão escolar. Nestes debates, informais, angústias, dificuldades, rejeições e aceitações se confundem com as possibilidades das escolas e as exigências legais do sistema educacional.

\section{Decisões metodológicas}

Este estudo descritivo se debruça na abordagem qualitativa, por se entender que as relações entre a realidade e o sujeito não podem ser traduzidas em números. Para Negrine (2004) a base analógica deste tipo de investigação se centra na descrição, análise e interpretação das informações recolhidas durante o processo investigatório, procurando entendê-las de forma contextualizada.

Ao levantar dados sobre a "mobilização dos saberes docentes na Educação Física Escolar: a construção do conhecimento sobre a inclusão", visamos conhecer os conceitos como também, a contribuição dos fatores cotidianos mediados pelos educadores.

Participaram como colaboradoras deste estudo, três professoras de Educação Física, escolhidas a partir de diferenças distintas representadas nos seus respectivos espaços de atuação, isto é, que possuíam ANEE incluídos em suas turmas de ensino regular da rede municipal, estadual e particular da cidade de Criciúma-SC.

A escolha destas colaboradoras e escolas aconteceu por conta do contato prévio, construído por visitas para orientação de acadêmicos do curso de Educação Física em situação de Estágio Curricular obrigatório de uma instituição de ensino superior. Este procedimento está em concordância com Molina (2004) que lembra de alguns cuidados que devemos ter com as escolhas do lugar da realização de uma investigação: aspectos práticos como o contato com o custo dos deslocamentos, disponibilidades dos documentos, etc.

Os nomes das professoras colaboradoras foram alterados por nomes fictícios para manter o sigilo da fonte. Para melhor compreensão do estudo apresentamos um breve perfil das professoras colaboradoras.

A professora Elizandra é solteira e possui 42 anos. Formou-se em Licenciatura Plena em 1991 na antiga Fundação Universitária de Criciúma (FUCRI), hoje Universidade do Extremo Sul Catarinense (UNESC) e sua 
Pós-Graduação teve como tema "Atividade Física, Promoção e Manutenção da Saúde" com término em 2002. Há 24 anos atua na área da Educação Física, e na escola em que a entrevistamos trabalha há 10 anos. Além desta, ela trabalha também em outra escola, fora do município.

A professora Heverlin possui 40 anos, é casada e tem uma filha de 12 anos. Formada desde 1994 em Licenciatura Plena, pela antiga FUCRI. Concluiu Pós-Graduação em 2003. Na escola que a entrevistamos trabalha há 10 anos, começou a dar aula logo depois de formada.

A professora Cintia possui 28 anos e é solteira. Formada em 2005 pela UNESC em Licenciatura Plena. Fez Pós-Graduação em Educação Física Escolar, na Escola Superior de Criciúma (ESUCRI) em 2008/2009. Há 6 anos atua na profissão e há 3 anos trabalha nesta escola, além da particular ela também trabalha em uma escola de rede municipal de Criciúma.

A análise dos dados coletados, por uma entrevista semi-estruturada, foi efetuada a partir da retirada de indicadores das respostas e levantamento de unidades de significado, que apontaram a construção das categorias de análise. Quanto ao instrumento para coleta de dados, Negrine (2004) observa que a entrevista, permite a explorações de informações, oferecendo liberdade ao entrevistado e visando garantir determinadas informações importantes para o estudo. Dado o exposto justifica a escolha da entrevista semi-estruturada, construída a partir dos objetivos do estudo.

Para realização da investigação, entramos em contato com as escolas para solicitar autorização às diretoras para que pudéssemos entrevistar as professoras na própria escola. Com a permissão concedida, falamos com cada uma das colaboradoras, explicamos os objetivos do estudo, e agendamos a data e o horário que as mesmas estivessem disponíveis para que pudéssemos realizar a entrevista. As entrevistas gravadas tiveram duração entre quinze a vinte minutos. As transcrições das entrevistas foram feitas no mesmo dia em que foram realizadas, por disponibilidade de horário naquele momento. Para Negrine (2004) os depoimentos e as respostas dadas devem ser transcritas com fidelidade, sem alterações dos vocábulos utilizados para que se evite a contaminação das informações.

As entrevistas transcritas foram enviadas as colaboradoras do estudo, procurando uma validação quanto ao real entendimento daquilo que se teve como resposta. Todo este procedimento utilizado para a coleta de informações, negociação de acesso, as entrevistas, a transcrição das entrevistas, as devoluções às respectivas entrevistadas e suas validações ocorreram sem nenhum impedimento durante o mês de outubro de 2011. 


\section{Os resultados a partir das categorias de análise}

\section{A opção pela formação em Educação Física: do passado ao presente}

Neste momento, passamos a apresentar à opção pela profissão e os motivos que levaram a escolha pela formação em Educação Física. Partimos do princípio que, escolher uma profissão não é uma tarefa fácil, precisamos ter motivos fortes e concretos para ajudar nesta decisão, onde, muitas vezes, o percurso de vida contribui na escolha de que caminhos seguir no futuro. A cada decisão tomada, somos invadidos de dúvidas, emoções, incertezas, ou até mesmo de influências do nosso convívio.

Para Soares (2002) a identidade é formada, nas relações estabelecidas entre pessoas que desempenham papéis sociais importantes na vida de cada indivíduo. Sendo assim, suas escolhas são construídas durante sua criação através de vínculos que são adquiridos pela sua trajetória de vida pessoal e profissional. Segundo Catani et al. (1997, p.34),

As concepções sobre as práticas docentes não se formam a partir do momento em que os alunos e professores entram em contato com as teorias pedagógicas, mas encontram-se enraizadas em contextos e histórias individuais que antecedem, até mesmo, a entrada deles na escola, estendendo-se a partir daí por todo o percurso de vida escolar e profissional.

Neste sentido, as professoras Elizandra e Heverlin comentaram que estavam sempre envolvidas com as atividades práticas nas aulas de Educação Física, influenciando a procura profissional a este campo.

"[...] eu gostava muito, da parte esportiva, da Educação Física, eu me destacava também, eu sempre gostei de esporte, desde pequena. Assim, na escola, me identificava nas aulas de Educação Física [...] E ai pensei, se for prá trabalhar com escola, vai ser direcionado à Educação Física" (Profa. Elizandra).

"Desde criança na verdade sempre gostei muito de tá jogando, participando de dança principalmente, [...], tudo que tinha tava presente, gostava muito de basquete também, e [...] gosto muito, da área da saúde, se não fosse Educação Física, seria alguma coisa relacionada à saúde, deu certo Educação Física, fiz gostei” (Profa. Heverlin). 
O contato com o esporte influenciou na escolha pela profissão docente em Educação Física. Podemos dizer que a identidade de cada indivíduo, ou a construção do saber, é definida muito antes de decidirmos qual carreira seguir. Tardif (2004) cita que uma boa parte do que os professores sabem sobre o ensino, sobre os papéis do professor e sobre como ensinar, provém de sua história de vida, principalmente de sua socialização enquanto alunos. Este interesse pelo saber tem um processo longo de vida, acompanhado de conhecimentos anteriores, crenças e atuações na sua vida pessoal e como aluno.

Conforme visto na fala das professoras Heverlin e Elizandra observamos que a opção pelo curso de Educação Física se manifestou principalmente pelas ricas experiências com atividades físicas na escola, e pelo incentivo que suas antigas professoras davam em participar dos jogos escolares, influenciando assim, em suas decisões. Para Tardif (2004) este é o saber temporal, é adquirido no contexto de uma história de vida e de uma carreira profissional.

Já a professora Cintia procurou a formação na Educação Física pela superação que ela teve no esporte durante as aulas enquanto aluna.

"[...] foi na quarta série, nunca esqueço que quando fui jogar vôlei levei uma bolada na cara e todo mundo começou a rir de mim (risos), aí a partir daquilo comecei a me superar, sempre querer praticar bastante esporte, comecei a gostar, comecei a sempre ser líder esportiva. Como me destacava nos esportes eles me escolhiam. Até levar esta bolada eu era meio patona, a bolada que me incentivou a procurar os esportes" (Profa. Cintia).

Alguns acontecimentos na vida fazem com que o sujeito desista de seguir adiante, deixando-os desmotivados a continuar. Com esta professora, o fato ocorrido marcou sua vida, incentivando a prática pelo esporte, influenciando muito em sua escolha pela profissão, escolha esta que definiu seu futuro, e trouxe muita satisfação, pois no decorrer da entrevista demonstrou bastante entusiasmo e interesse pelo que faz.

Tardif (2004) observa que muitas pesquisas mostram que este saber herdado da experiência escolar anterior é muito forte, que ele persiste através do tempo e que a formação universitária não consegue transformála. De acordo com o autor supracitado a experiência herdada tem uma forte influência na escolha profissional, e que boa parte do que os professores sabem, é devido a sua história de vida e socialização enquanto aluno. As colaboradoras desta pesquisa, em sua vida escolar estavam diretamente envolvidas na prática, junto ao esporte, tendo um conhecimento e se 
apropriando do saber docente, dando continuidade a este saber na sua vida profissional.

\section{O conhecimento dos professores de Educação Física para a regência com os alunos incluídos}

A apresentação desta categoria de análise tornou-se importante, à medida que foi manifestado, pelas colaboradoras, um desapontamento com a graduação, considerada insatisfatória na construção do saber docente e na preparação do professor para a realidade escolar. Através das falas, percebemos que o professor de Educação Física além de sua formação, ele deve buscar conhecimentos em outros meios, pois somente a graduação não é suficiente para construção do saber do professor com os ANEE. Segundo as professoras colaboradoras, elas não tiveram nenhuma disciplina que pudesse contribuir para sua prática educativa frente à inclusão escolar.

As professoras Elizandra e Heverlin afirmaram que tiveram apenas o estágio obrigatório durante o percurso acadêmico, onde tiveram algum conhecimento quanto aos ANEE.

"[...] disciplina para trabalhar com eles (ANEE), eu não tive, tu vai buscar depois, através de cursos, formação, palestras, mas não tive [...] a única disciplina que tive relacionado à inclusão, foi o estágio, aquele que tu entra na escola e [...] te vira" (Profa. Elizandra).

"Não, inclusão escolar não, a única coisa que a gente fez foi estágio em escola especial, [...], mas inclusão, uma disciplina com a inclusão, nenhuma" (Profa. Heverlin).

As professoras Heverlin e Elizandra argumentaram que durante sua formação elas não tiveram nenhuma disciplina direcionada à inclusão, mas adquiriram algum conhecimento sobre necessidades especiais, através do estágio obrigatório em uma escola especial. A professora Elizandra comentou ainda, que não teve nenhuma orientação dos professores antes e durante sua atuação no estágio obrigatório.

Os estágios em escolas especiais contribuem para construção do saber do professor para a prática educativa frente a inclusão. Normalmente é através dos estágios que o acadêmico tem o primeiro contato com ANEE, é onde ele começa a ter a ideia das dificuldades e de que maneira que pode ser trabalhada a inclusão em classes comuns, conhecendo os limites e as possibilidades de cada caso. 
A professora Cintia contou que teve duas disciplinas direcionadas à inclusão na sua formação e também o estágio obrigatório em escola especial. Relatou que estas disciplinas contribuem de alguma forma, mas que não são suficientes para chegar na escola e conseguir fazer um bom trabalho com os ANEE. Estes são os saberes disciplinares, que, para Tardif (2004), se integram igualmente à prática docente através de formação (inicial e continuada) dos professores nas diversas disciplinas oferecidas pela universidade.

"Eram duas se não me engano [...] só que no meu estágio na área da inclusão achei bem difícil, a prática, não foi uma coisa que me identifiquei, mas foi [...] bom para o conhecimento" (Profa . Cintia).

A professora Cíntia, a mais recente graduada dentre as colaboradoras, formada em 2005, foi à única a ter alguma disciplina em sua formação relacionada à inclusão escolar de ANEE. Desta forma, notamos que a formação inicial vem sendo inovada, transformada, com um interesse maior para que todos tenham direito pela educação, acrescentando na grade curricular do ensino superior, disciplinas que tratam sobre o trabalho pedagógico frente à inclusão escolar. O professor começa a ter contato com a realidade da sua profissão ainda no período dos estágios, para conhecer os espaços em que vai dedicar parte de sua vida.

Segundo Pereira (2000) o Estágio Curricular Supervisionado é o momento de integração da Licenciatura com a realidade dos sistemas escolares. É através e durante os estágios que o acadêmico passa a ter o contato com sua vida profissional. Portanto, as professoras colaboradoras passaram por este momento de conhecimento do seu ambiente de trabalho, na vida acadêmica como foi mostrado nesta categoria, todas tiveram estágios com a Educação Especial, mas nada que pudesse ensinar a elas, qual o caminho ideal para ser trabalhada a inclusão nas aulas de Educação Física.

\section{A busca do conhecimento pelos professores de Educação Física: a prática educativa como mobilizadora de saberes docentes}

Neste momento, apresentamos através das informações coletadas, a participação das professoras colaboradoras em programas de formação continuada e a prática como construtora dos saberes. Para muitos a formação termina quando se conclui a graduação, na verdade ainda existe uma longa caminhada, procurando conhecimento para ter domínio de situações que poderão intervir no seu trabalho. 
"É, sempre se faz cursos, mas aqui a gente tem bem poucos relacionados à inclusão de alunos especiais, a gente não tem muitos cursos relacionado a este lado não" (Prof ${ }^{a}$ Elizandra).

Para a professora Elizandra os cursos não são suficientes para o papel do professor na produção do saber. Os professores precisam de oportunidades para refletir sobre as propostas de mudança que mexem com seus valores e com suas convicções, assim como aquelas que afetam sua prática profissional cotidiana (MITTLER, 2003). O ideal seria preparar os professores para seu trabalho, deixando-os sempre atualizados de seus novos compromissos. Para que isto aconteça, o essencial é proporcionar cursos de formação continuada, contribuindo com o saber docente.

Segundo Cristine (2011) quando se refere à formação continuada, são enfatizados os seguintes aspectos dos profissionais: a formação, a profissão, a avaliação e as competências que cabem ao profissional. $O$ educador que está sempre em busca de uma formação contínua, bem como a evolução de suas competências tende a ampliar o seu campo de trabalho.

Mazzeu (1998) comenta que o processo de formação continuada de professores que está se propondo aqui se concentra em três eixos básicos: 1) O domínio do saber acumulado no que se refere ao conteúdo escolar e às formas de ensiná-lo; 2) O domínio da concepção dialética como meio de desenvolver uma ação e uma reflexão autônomas e críticas; e, 3) A formação de uma postura ética-política por sentimentos e valores que possibilitem ao professor utilizar este saber acumulado como meio para o desenvolvimento pleno do aluno e para seu próprio desenvolvimento como ser humano.

A professora Heverlin teve uma opinião diferente em relação à disponibilidade de cursos.

"[...] tem vários cursos em relação à inclusão [...] O da pós ajudou bastante, até porque a gente viu, as deficiências a evolução que elas podem ter [...] Mas é na parte prática que a gente aprende muito mais, imagina tu vai lá faz os cursos e tal, tu sempre aprende algumas coisinhas, mas a prática faz muita diferença" (Prof ${ }^{a}$ Heverlin).

Para Tardif (2004) tais experiências são adquiridas com o tempo e com a experiência de trabalho. É no dia a dia, trabalhando, que se constrói grande parte do conhecimento. Conforme o autor, estes são os saberes experienciais, que no exercício cotidiano de sua função, os condicionamentos 
aparecem relacionados a situações concretas que não são passíveis de definições acabadas e que exigem improvisação e habilidade pessoal.

Constata-se então, que a prática se torna um grande avanço no saber do professor, proporcionando ao docente, auto-confiança em tomar atitudes devido algumas situações geradas em suas aulas.

Bueno (2002), afirma que não são somente os programas de formação de professores que contribuem para a construção da identidade docente, mas também a experiência de vida destes docentes relacionadas a educação e ao ensino.

Existe uma contradição entre as colaboradoras, quanto a formação permanente, pois na opinião da professora Elizandra os cursos disponibilizados são poucos, no entanto a professora Heverlin comentou que existem muitos cursos para que possam se apropriar de conhecimentos. Portanto, englobando todas as informações coletadas das professoras colaboradoras quanto à procura por conhecimento, notamos que os cursos contribuem para conhecer as dificuldades, as limitações e as possibilidades encontradas em cada caso de inclusão, mas as colaboradoras afirmaram que é na prática que se aprende, é na prática que vão adquirindo conhecimento para trabalhar com os ANEE.

Pereira (2000) comenta que a formação do professor não termina com a sua diplomação na agência formadora, mas completa-se em serviço. A seguir o relato da professora Cintia:

"Curso, fiz um de inclusão, e é mais na prática mesmo, quando tu se depara com aluno, ai tu vai buscar, ou vai procurar entender mais sobre aquela deficiência [...] Acho que contribui, mas acho que quando vai prá prática mesmo e ver qual é a realidade [...]" (Prof ${ }^{a}$ Cintia).

Para Mittler (2003) é durante o percurso profissional que os professores constroem e ampliam suas habilidades, ampliam as experiências que já possuem com o objetivo de alcançar todas as crianças e suas necessidades de aprendizagem. A professora Elizandra relatou que as formações ajudam a conhecer os limites e oportunizam a reflexão sobre o trabalho pedagógico com o ANEE.

"Tu consegues identificar, às vezes, o problema, mas o teu dia-a-dia trabalhar os esportes é complicado, tem que ir à prática e tentar buscar as coisas, porque assim é muito bonito no papel, vem prá cá é uma luta [...] $A$ 
realidade mesmo é a gente que tem que buscar, é a prática [...] sinceramente eu não tenho preparo prá trabalhar com a inclusão, não é que a gente não vai em busca [...]" (Profa Elizandra).

Segundo a professora Heverlin para que haja a inclusão ela desenvolve várias alternativas metodológicas para trabalhar com os ANEE.

"Eu procuro conversar bastante com eles assim prá insistir [...], dou mais atenção prá este, que não tá querendo fazer, porque são poucos os casos mas existe. [...], dou algum trabalho prá eles, às vezes, escrito" (Prof ${ }^{a}$ Heverlin).

Conforme os dados desta categoria, podemos dizer que o saber da experiência são mobilizados sempre que as professoras se deparam com situações conturbadas da prática educativa. Elas mesmas criaram maneiras e possibilidades para que o aluno seja aceito na sua turma e na escola. É preciso que os professores tenham mais oportunidades de aperfeiçoamento em sua formação, atualizando-se devido às mudanças em sua profissão, para que possam utilizar deste saber proporcionando uma convivência prazerosa entre os alunos incluídos com toda a comunidade escolar, além de estarem preparando este aluno para viver em sociedade.

\section{A inclusão: as dificuldades encontradas na escola pelos professores de Educação Física}

Através desta categoria, observamos onde cada professora colaboradora sente dificuldade em trabalhar a inclusão na escola, e quais as situações que podem ajudar estas professoras a incluir os ANEE na turma durante suas aulas.

A professora Elizandra comentou que a inclusão só acontece se o aluno aceitar, isso pode depender de cada deficiência do ANEE, alguns podem ser de fácil socialização, outros podem apresentar uma certa rejeição na inclusão, sendo o professor o mediador deste saber para conquistar a inclusão no decorrer do desenvolvimento das aulas.

"[...] depende muito também da criança né de como ela é, que tem criança que interage, mas tem criança que não [...]" (Prof' Elizandra).

Ela afirmou ainda que, muitas vezes, a inclusão não é possível por falta de espaço adequado para a prática. Conforme Mittler (2003, p. 25), 
[...] no campo da educação, a inclusão envolve um processo de reforma e de reestruturação das escolas como um todo, com o objetivo de assegurar que todos os alunos possam ter acesso a todas as gamas de oportunidades educacionais e sociais oferecidas pela escola.

O autor ainda aborda que isto inclui o currículo corrente, a avaliação, os registros e os relatórios de aquisição acadêmicas dos alunos, bem como as oportunidades de esporte, lazer e recreação.

Elizandra comentou ainda que:

"[...] os alunos sentem dificuldades, tu não consegue trabalhar um esporte direito, tu não consegue não tendo uma quadra, vai ficar só em brincadeiras e jogos, é difícil claro, mas, enfim, e os mais velhos a idade ali que vai pedindo, eles não querem um basquete, um vôlei, tudo improvisado" (Profa Elizandra).

Baseando-nos na fala desta professora, percebemos que a inclusão é mais fácil de trabalhar os alunos enquanto são pequenos, a partir do momento em que vão crescendo, passando de ano, se torna mais difícil, pois os ANEE e os ditos "normais" acabam querendo aprender mais, e devido ao local para a prática se torna difícil de fazer a inclusão, no caso desta escola.

A professora Cintia relatou também que enquanto são pequenos se torna mais fácil de incluí-los.

"[...] quanto menores eles são, mais compreensivos os colegas são, porque já começa a criar um hábito de convivência com aquela crinança desde pequena. Às vezes a criança olha com um olhar diferente, mas depois eles vão conhecendo mais o coleguinha, vão se adaptando, respeitando os limites" (Prof Cintia).

Podemos observar que a inclusão no que se refere aos colegas é bem aceita, todos constroem uma amizade e aceitam as diferenças, tendo curiosidade, às vezes, em saber por que o colega é diferente, mas sem preconceito e contribuindo para sua inclusão.

Perguntamos às professoras colaboradoras se os pais dos ANEE reconhecem o trabalho delas na escola com seus filhos, se existe alguma preocupação da parte dos pais em saber se o filho está tendo alguma evolução nas aulas. 
Elizandra ao responder esta pergunta demonstrou certo desânimo.

"Não tem esta preocupação de saber como que tá o filho [...] Fica mais difícil [...] não sei se a gente já vem de uma sociedade até que os pais, às vezes, já rejeitam, não aceitam o filho assim [...]" (Profa Elizandra).

"Eu sempre converso com as mães, estas duas mães, que eu tenho este ano, elas sempre vem conversar comigo, elas perguntam como é que eles estão e tal, às vezes, até perguntam, o que eu posso fazer prá tá ajudando um pouquinho em casa [...], eu acho que elas se importam, que se preocupam, que dão uma atenção" (Profa Heverlin).

"É, eles sempre vêm na escola [...], sempre tenho apoio da direção e dos pais" (Prof Cintia).

Diante das respostas das professoras colaboradoras, a maioria dos pais são participativos na vida escolar do filho, mas ainda contamos com alguns pais desinteressados em saber como o filho está se desenvolvendo diante das atividades propostas pelos professores. Este contato com a escola e com os professores ajuda na evolução do aluno. No caso da professora Heverlin, ela tem a participação dos pais na obtenção de informações de como o filho é em casa, para saber como ela pode agir com ele na escola, estas informações podem contribuir muito no desenvolvimento e socialização do ANEE.

Os professores têm a obrigação e a necessidade de avaliar os alunos, para conhecê-los e saber de seus progressos, possibilitando a identificação do que ainda precisa ser trabalhado. Além disso, a avaliação é um instrumento para possíveis revisões no processo de ensino, ou seja, uma análise avançada sobre a prática pedagógica do professor. Sendo assim, perguntamos às professoras colaboradoras de que forma elas avaliam os ANEE, principalmente aqueles que possuem algum tipo de necessidades especiais que, muitas vezes, não conseguem fazer alguma atividade na prática.

"[...] em termos de avaliação, a gente nunca teve uma explicação de como avaliar na Educação Física, porque é bem complicado, se tu parte da teoria e tu dá conteúdo, tudo bem tu cobra, aí o que tu avalia? Tu avalia comportamento, tu avalia a participação do aluno, tu avalia a disciplina deles, o respeito, mas em termos de rendimento, não tem como tu avaliar, tipo, o porque o aluno não rende, não sabe, o aluno não consegue. Não consegue agora, mas depois ele consegue, são passos, principalmente os pequenos, 
os pequenos tu não vê de uma hora prá outra, a resposta é uma coisa mais demorada" (Prof ${ }^{a}$ Elizandra).

$\mathrm{Na}$ fala desta professora percebemos uma dificuldade em avaliar os ANEE, pois a avaliação, para muitos docentes, parte do principio que se avalia através da evolução dos alunos, mas muitos casos de ANEE a evolução é lenta, para ver resultados é mais demorado.

"Não só prática, às vezes, dou algum trabalho prá eles escrito, ou o próprio rendimento deles aos pouquinhos, porque infelizmente não é porque eles não querem né, a gente sabe as dificuldades deles, a limitação" (Prof ${ }^{a}$ Heverlin).

"A avaliação é descritiva, eu busco sempre falar o desenvolvimento da criança, quais os processos, a evolução que ela teve durante o trimestre, independente da série é descritiva" (Profa Cintia).

As professoras colaboradoras avaliam através de práticas, teorias, participação dos alunos e respeito. O método de avaliação depende de cada escola decidir de que forma avaliar o aluno, quais os meios que serão mais precisos para identificação da evolução conquistada por eles se é através de notas ou avaliação descritiva.

A professora Heverlin abordou durante a entrevista alguns casos de inclusão que teve no decorrer de sua carreira.

"[...] tive crianças especiais, na outra escola também, até era mental severo, foi bem complicado de trabalhar, porque ela não parava, queria fazer tudo do jeito dela, é bem difícil [...] o problema maior é quando o problema é mental [...]".(Profa Heverlin).

"[...] tanto estes dois alunos que tenho, eles não tem problema mental, então eles entendem o que tu fala o que tu diz, é bem tranqüilo em relação ao entendimento deles [...]" (Prof ${ }^{a}$ Heverlin).

Esta professora comentou que gosta de estar sempre dando atenção para os ANEE, se eles não conseguem fazer do jeito que ela explicou, ela pede para que tentem de outro jeito, mas que se esforcem em fazer.

"Eu procuro conversar bastante com eles prá insistir, eu sou daquelas bem chata, que tá sempre conversando perguntando, há porque 
tu não quer fazer, vai lá fazer, ensino, dou mais atenção prá este que não tá querendo fazer [...]", mas assim, eu não tenho uma aluna, eu tenho trinta [...]" (Prof ${ }^{\mathrm{a}}$ Heverlin).

O professor além de não estar preparado para trabalhar com a inclusão, ainda passa por situações em que o número de alunos é alto para poder desenvolver o que sabem, situações que se torna complicado de conseguir dar atenção a este aluno. Atenção esta que poderia fazer com que o aluno tivesse um progresso mais rápido, pois se o professor consegue dedicar grande parte de sua aula para o aluno incluído, ele terá, também, além da dedicação do professor, uma motivação maior e entusiasmo para conquistar aquele certo movimento em devidas atividades e ter uma melhor socialização com os colegas. Se o professor conseguir ter essa aproximação com o ANEE no inicio do ano letivo, a conquista por uma aceitação e dedicação do próprio ANEE nas aulas se torna mais fácil e mais rápido.

Com todas as informações mostradas nesta categoria, podemos dizer que são muitas as dificuldades encontradas ainda nesta longa jornada. Cada professora colaboradora apresentou alguma dificuldade, tanto com os pais, espaço impróprio na escola para a prática, métodos de avaliação ou até mesmo dos próprios ANEE. Os professores sozinhos nesta caminhada tornase mais difícil de realizar um bom trabalho.

Para Voivodic (2004) o termo inclusão, do verbo incluir, significa compreender, fazer parte de, ou participar. Participação é uma necessidade fundamental do ser humano, e o homem só terá possibilidade de total desenvolvimento numa sociedade que permita e facilite sua participação. Portanto, para que os professores possam fazer a inclusão acontecer eles precisam da colaboração de toda comunidade escolar, dos pais e do poder público, podendo assim desenvolver um trabalho com muito sucesso.

\section{Considerações transitórias}

Ao retomar o objetivo deste estudo (compreender como os professores buscam o conhecimento sobre a inclusão, para atuar com ANEE nas aulas de Educação Física em suas turmas comuns do ensino fundamental), compreendemos como os saberes docentes são mobilizados pelas professoras, para dar conta da inclusão escolar.

As informações coletadas mostraram que as professoras colaboradoras do estudo, mobilizaram seus diferentes saberes no momento que entraram em contato com a inclusão escolar. Neste contato, a prática 
educativa foi alimentada pelo saber experiencial e curricular. Nesta análise, encontramos que o conhecimento sobre o tema inclusão quando não trabalhado na formação inicial, foi construído através de atividades de formação permanente.

Amobilização dos saberes docente, pelas professoras colaboradoras da pesquisa, quando tratados para dar conta da inclusão escolar ocorreram a partir da experiência, na prática educativa, na construção e compreensão das necessidades educacionais dos professores.

Através dos dados coletados, vimos que todas as professoras colaboradoras tiveram um contato direto com a Educação Física durante sua vida escolar e com o esporte de rendimento, e isto fez com que as mesmas optassem pela formação na área. Através do curso de graduação elas observaram que é muito importante a disciplina da Educação Física na escola, pois que é fundamental na fase de crescimento dos alunos, melhorando o convívio social, integrando e propiciando a formação de amizades entre os mesmos.

\section{Referências}

BUENO, B. O. O método autobiográfico e os estudos com histórias de vida de professores: a questão da subjetividade. Revista Educação e Pesquisa, São Paulo, 2002.

CATANI, D. B. et al. Docência, memória e gênero. São Paulo: Escrituras, 1997.

CRISTINE, E. A importância da formação contínua. Disponível em: http:// www.mundoeducacao.com.br/educacao/a-importancia-formacao-continua. htm . Acessado em: 20/11/11.

DECLARAÇÃO DE SALAMANCA. Sobre os princípios, políticas e práticas na área das necessidades educativas especiais. España: Salamanca, 1994.

FREIRE, P. Conscientização: teoria e prática da libertação: uma introdução ao pensamento de Paulo Freire. São Paulo: Centauro, 2001.

GAUTHIER, C. Por uma teoria da pedagogia: pesquisas contemporâneas sobre o saber docente. ljuí: UNIJUÍ, 1998. 
MAZZEU, F. J. C. Uma proposta metodológica para a formação continuada de professores na perspectiva histórico-social. Caderno CEDES, Campinas, v.19, n.44, abr., 1998.

MAZZOTA, M. J. S. Trabalho docente e formação de professores de Educação Especial. São Paulo: E.P.U., 1993.

MITTLER, P. Educação inclusiva, contexto sociais. Porto Alegre: Artmed, 2003.

NEGRINE, A. Instrumentos de coleta de informações na pesquisa qualitativa. In: MOLINA NETO, V.; TRIVIÑOS, A.N.S. (Orgs.). A pesquisa qualitativa na Educação Física: alternativas metodológicas. 2. ed. Porto Alegre: UFRGS/ Sulina, 2004.

MOLINA, R. M. K. O enfoque teórico metodológico qualitativo e o estudo de caso: uma reflexão introdutória. In: MOLINA NETO, V.; TRIVIÑOS, A.N.S. (Orgs.). A pesquisa qualitativa na Educação Física: alternativas metodológicas. 2. ed. Porto Alegre: UFRGS/Sulina, 2004.

PEREIRA, J. E. D. Formação de professores: pesquisas, representações e poder. Belo Horizonte: Autêntica, 2000.

SOARES, D. H. P. A escolha profissional do jovem e do adulto. São Paulo: Summus, 2002.

TARDIF, M. Saberes docentes e formação profissional. 4. ed. Petrópolis: Vozes, 2004.

VOIVODIC, M. A. Inclusão escolar de crianças com síndrome de down. 3 ed. Petrópolis: Vozes, 2004.

\section{Correspondência}

Victor Julierme Santos da Conceição - Universidade do Extremo Sul Catarinense, Departamento de Educação Física.

Av Universitária, Universitário, CEP: 88803-000 - Criciuma, Santa Catariana - Brasil.

E-mail: victorjulierme@hotmail.com - hnkrug@bol.com.br - ednavenson@hotmail.com

Recebido em 21 de setembro de 2012

Aprovado em 18 de março de 2013 